\title{
Physical Therapists' Nonverbal Communication Predicts Geriatric Patients' Health Outcomes
}

\section{Citation}

Ambady, Nalini, Jasook Koo, Robert Rosenthal, and Carol H. Winograd. 2002. Physical therapists' nonverbal communication predicts geriatric patients' health outcomes. Psychology and Aging 17, no. 3: 443-452.

\section{Published Version}

http://dx.doi.org/10.1037/0882-7974.17.3.443

\section{Permanent link}

http://nrs.harvard.edu/urn-3:HUL.InstRepos:3219882

\section{Terms of Use}

This article was downloaded from Harvard University's DASH repository, and is made available under the terms and conditions applicable to Other Posted Material, as set forth at http:// nrs.harvard.edu/urn-3:HUL.InstRepos:dash.current.terms-of-use\#LAA

\section{Share Your Story}

The Harvard community has made this article openly available.

Please share how this access benefits you. Submit a story.

Accessibility 


\title{
Physical Therapists' Nonverbal Communication Predicts Geriatric Patients' Health Outcomes
}

\author{
Nalini Ambady and Jasook Koo \\ Harvard University
}

\author{
Robert Rosenthal \\ University of California, Riverside
}

\author{
Carol H. Winograd \\ Stanford University
}

\begin{abstract}
Two studies explored the link between health care providers' patterns of nonverbal communication and therapeutic efficacy. In Study 1, physical therapists were videotaped during a session with a client. Brief samples of therapists' nonverbal behavior were rated by naive judges. Judges' ratings were then correlated with clients' physical, cognitive, and psychological functioning at admission, at discharge, and at 3 months following discharge. Therapists' distancing behavior was strongly correlated with short- and long-term decreases in their clients' physical and cognitive functioning. Distancing was expressed through a pattern of not smiling and looking away from the client. In contrast, facial expressiveness, as revealed through smiling, nodding, and frowning, was associated with short- and long-term improvements in functioning. In Study 2, elderly subjects perceived distancing behaviors of therapists more negatively than positive behaviors.
\end{abstract}

It is now widely accepted within the medical profession that treatment regimen alone cannot fully account for patient outcome. Indeed, the notion that interpersonal communication between the patient and the physician plays a major role in patient outcome has recently received a great deal of attention, including an abundance of research focusing on ways to improve physicians' interpersonal communication skills (DiMatteo \& Friedman, 1982; Friedman \& DiMatteo, 1982; Maguire, Fairburn, \& Fletcher, 1986; Robbins \& Woolf, 1989). This research has established an empirical link between patients' satisfaction with their physicians' communication style and their adherence to prescribed treatment, essential to their recovery (Greenfield, Kaplan, \& Ware, 1985; Greenfield, Kaplan, Ware, Yano, \& Frank, 1988; Kaplan, Greenfield, \& Ware, 1989). Effective physician-patient communication is associated with both increased psychological well-being (Devine \& Cook, 1985; Mumford, Schlesinger, \& Glass, 1982) and better biomedical outcomes (Greenfield, Kaplan, \& Ware, 1985; Greenfield et al., 1988; Kaplan et al., 1989) for the patient. Poor physician-

Nalini Ambady and Jasook Koo, Department of Psychology, Harvard University; Robert Rosenthal, Department of Psychology, University of California, Riverside; Carol H. Winograd, School of Medicine, Stanford University.

Thanks to Stephanie Levin, Gauri Desai, Heather Gray, Elizabeth Johnson, and Mark Hallahan for their assistance and support. This research was supported by a grant from the John A. Hartford Foundation to Carol H. Winograd and a Presidential Early Career Award for Scientists and Engineers award to Nalini Ambady from the National Science Foundation, Grant BCS 9733706.

Correspondence concerning this article should be addressed to Nalini Ambady, Department of Psychology, 33 Kirkland Street, Harvard University, Cambridge, Massachusetts 02138. E-mail: na@wjh.harvard.edu patient communication, on the other hand, is costly and can lead to negative consequences such as patient dissatisfaction, doctor shopping, poor adherence to medical directions, and malpractice litigation (Lepper, Martin, \& DiMatteo, 1995; White, Levinson, \& Roter, 1994; Woolley, Kane, Hughes, \& Wright, 1978).

Effective physician-patient communication is especially important when the patient is an older adult, due to physical, cognitive, and psychological factors unique to the aging patient. For example, elderly patients often present with more complicated medical conditions that require multiple prescriptions, necessitating a more thorough explanation of the treatment regimen. In this case, effective physician-patient communication is crucial in avoiding poor patient recall of information (Levinson, 1994). The physical signs of aging, including hearing, visual, and cognitive impairments, may act as a barrier to effective physician-patient communication and thus heighten the need for careful detailed explanations by physicians. Psychological intergenerational differences complicate the physician-patient interaction even further. For instance, elderly clients tend to be less assertive and more passive in their interactions with physicians (Beisecker \& Beisecker, 1990), perhaps because of fear of being perceived as disrespectful. This presents a problem when a medical explanation requires further clarification and the patient is reluctant to ask for it. Finally, elderly clients are often unwilling to broach personal topics that might be relevant to their heath care status (German et al., 1987). Thus, investigation into the factors involved in successful interactions between health care provider and elderly clients is clearly warranted.

\section{Physician Communication Style}

Unfortunately, much of the research on doctor-patient communication indicates that physicians' speech to elderly clients is often characterized by a dismissive patronizing communication style. 
Greene, Adelman, Charon, and Hoffman (1986), for instance, found that physicians are less respectful, patient, and supportive of their older patients relative to their younger patients. Along the same lines, Adelman, Greene, Charon, and Friedmann (1992) reported that physicians initiate the majority of conversation topics when speaking to elderly patients and that physicians are less responsive to the topics initiated by elderly patients. In examining the particular communicative behaviors of physicians, researchers have found that speech to the elderly is often perceived as overly simplistic and patronizing (Adelman et al., 1992; Caporael, 1981; Caporael \& Culbertson, 1986; Coupland, Coupland, \& Giles, 1984). When speaking to the elderly, heath care providers often modify their speech patterns in accordance with stereotypes of the elderly as less competent and more dependent (Kite \& Johnson, 1988; Kogan, 1979; Levin, \& Levin, 1980; Rubin \& Brown, 1975). An extreme form of this patronizing speech pattern is "secondary baby talk" associated with infantilization of the elderly (Caporael, Lukaszewski, \& Culbertson, 1983), characterized by the high pitch and exaggerated intonation usually reserved for speech to infants. Caporael (1981) found that the relative frequency of the use of baby talk to the elderly is as high as $20 \%$. As part of the same investigation, college students were unable to distinguish between content-filtered speech samples of primary baby talk (to toddlers) and secondary baby talk (to the elderly). It is not surprising, then, that in a recent study, elderly participants named the doctor's office as one of the situations in which they feel patronized most often (Hummert \& Mazloff, 1993).

\section{Provider Communication Style and Elderly Patient Outcome}

Despite the findings reviewed above indicating that poor communication by health care providers is often associated with decreased patient satisfaction with the health care encounter, little attention has been paid to the effects of providers' communication on actual health outcomes for elderly patients. No studies, to our knowledge, have delineated the particular caregiver communicative behaviors associated with better or worse outcomes for elderly clients. The first goal of this article, then, is to examine more directly the relationship between health care providers' communication and health outcomes of elderly clients. In an effort to meet this goal, direct observations of provider communicative behavior were essential.

\section{Thin-Slice Judgments of Nonverbal Behaviors}

Considerable evidence suggests that judgments based on brief excerpts or thin slices of behavior extracted from the ongoing behavioral stream can be quite reliable and accurate. Thin slices are samples of expressive behavior, which is chronic, reliable, stylistic, and often not subject to conscious control and monitoring (DePaulo, 1992; Ekman \& Friesen, 1969, 1974; Rime \& Schiaratura, 1991). A meta-analysis of a number of studies that used thinslice judgments revealed that the overall effect sizes associated with thin-slice judgments $(r=.39)$ do not differ significantly from effect sizes obtained from much longer observations (Ambady \& Rosenthal, 1992).

A number of studies that used thin-slice judgments have shown that such judgments are predictive of outcomes in health care settings (Ambady, Bernieri, \& Richeson, 2000; Ambady \& Rosenthal, 1992). For example, ratings of anxiety from thin slices of physicians' voices predict their success in referring clients (Milmoe, Rosenthal, Blane, Chafetz, \& Wolf, 1967). Other studies have shown that thin-slice ratings of physicians' behavior predict patient satisfaction (Hall, Roter, \& Rand, 1981) and providers' expectations regarding clients (Blanck, Rosenthal, \& Vannicelli, 1986).

Practitioner effectiveness can also be judged from thin slices (Rosenblum et al., 1994; Tickle-Degnen, 1998). Thus, for example, Rosenblum et al. (1994) found that ratings of six 15-s slices of medical students in a pediatric clerkship videotaped interviewing adult patients, predicted the grades assigned by their clinical supervisors. In another study, thin-slice judgments of 15-s clips of occupational therapy students predicted their clinical performance (Tickle-Degnen, 1998; Tickle-Degnen \& Puccinelli, 1999). Moreover, these thin-slice judgments proved sensitive enough to distinguish between specific therapist attributes uniquely suited to specific clinical contexts. Specifically, students who were judged as less nonverbally responsive and more dominant were more effective in a pediatric rehabilitation setting, whereas less friendly students were more effective in a physical rehabilitation context. On the basis of these findings, suggesting the usefulness of thinslice judgments in predicting outcomes related to health care, we investigated whether thin-slice ratings of physical therapists' behaviors during their interactions with elderly clients were related to physical and cognitive outcomes of the clients.

Providers' specific nonverbal behaviors have been found to predict clients' satisfaction and impression of the physician (Roter, Hall, \& Katz, 1987). Such behaviors may contribute to the development of trust and rapport and to the establishment and maintenance of interpersonal relationships with clients (Ambady \& Rosenthal, 1992; Hall, Harrigan, \& Rosenthal, 1995). Metaanalytic work suggests that greater client satisfaction is associated with more nonverbal immediacy (as indexed by forward leans, direct eye contact, direct body orientation, and less interpersonal distance) and attention from physicians (Hall \& Dornan, 1988). Satisfaction has also been related to nonverbal behaviors thought to convey encouragement and interest such as head nods, open arm position, and forward leans (Harrigan \& Rosenthal, 1983; Larsen \& Smith, 1981; Weinberger, Greene, \& Mamlin, 1981). Other nonverbal behaviors, including eye contact, gestures, and posture, have also been implicated in the therapeutic process. Specific behaviors have been associated with perceptions and ratings of providers. Eye contact, for example, has been related to higher ratings of counselor respect and genuineness (Kelly \& True, 1980), empathic qualities (Hasse \& Tepper, 1972; Seay \& Altekruse, 1979; Tepper \& Hasse, 1978; Timpton \& Rymer, 1978), and overall ratings of positivity (Harrigan, Oxman, \& Rosenthal, 1981); therapist nodding appears to be associated with clients' feelings of support and accomplishment (Hill \& Stephany, 1990) and other positive consequences (D'Augelli, 1974; Harrigan \& Rosenthal, 1983; LaCrosse, 1975); and body position has been related to more favorable ratings of counselors (Fretz, Corn, Tuemmler, \& Bellet, 1979; Harrigan \& Rosenthal, 1983; Harrigan et al., 1985; Hasse \& Tepper, 1972; Hermansson, Webster, \& McFarland, 1988; Tepper \& Hasse, 1978) and to counselors' warmth and empathy ratings (Smith-Hanen, 1977). Given the importance of these provider behaviors to clients' perceptions and 
satisfaction, it seems important to further investigate them in relation to elderly patients. Again, although perceptions and satisfaction associated with such behaviors have been investigated, there has been a paucity of work relating such behaviors to actual health care outcomes. Thus, a second goal of the present work is to investigate the relationship between physical therapists' specific nonverbal behaviors such as smiling and frowning and the health outcomes of geriatric clients.

In sum, this study seeks to expand the research on providerclient communication by examining (a) the relationship between health care providers' (physical therapists) communicative behaviors in actual interactions with their clients and elderly clients' health care outcomes, and (b) the relationship between specific nonverbal behaviors of providers as rated from actual interactions with their clients and elderly clients' health care outcomes.

\section{Study 1: Physical Therapists' Behaviors and Clients' Outcomes}

\section{Method}

\section{Overview}

In this study, physical therapists and their clients were videotaped interacting during a therapy session. From these videotapes, thin slices (three 20-s clips) of therapists' behavior were extracted and then evaluated by naive judges. We examined correlations between judges' ratings of the physical therapists' communicative and specific nonverbal behaviors with several measures of clients' physical, cognitive, and psychological functioning taken at admission, discharge, and 3 months following discharge.

\section{Phase 1: Creating Stimuli}

Participants (targets). Interactions between 48 clients ( 28 female, 20 male) and 11 physical therapists ( 8 female, 3 male) were rated in this study. Clients were all 75 years old or over, had ambulated independently with or without aids 2 weeks prior to admission to Stanford University Hospital, but had demonstrated recent decline in mobility and were unable to walk 300 feet or more without assistance. Clients began physical therapy within $48 \mathrm{hr}$ of admission and stayed in hospital an average of 9.3 days. The first or last therapy session was videotaped, and the camera was in the room and was focused on the therapist. Both the therapists and the clients knew that the sessions were being recorded. Informed consent was obtained from the clients.

Outcome measures. Outcome measures evaluated patients' physical, cognitive, and psychological functioning. Physical and cognitive measures were administered at admission, discharge, and 3 months following discharge. These included two self-report measures (to evaluate mobility and the ability to carry out activities of daily living) and one interview measure (confusion assessment) described below. Psychological functioning measures were taken only at discharge (due to logistical issues, these measures could not be completed at admission); physical and cognitive measures were repeated across 3 time periods. By computing the proportion of change from admission to discharge and from admission to 3 months after discharge using the admission score as a baseline, were able to derive an index of improvement for each patient. Thus, the improvement score at discharge would be the difference between the admission and the discharge score divided by the admission score.

\section{Physical Functioning}

Mobility assessment. A self-report measure assessed physical functioning by using 10 items that evaluate difficulties in performing a range of physical activities, such as walking across a room, getting out of a chair, and sitting up in bed (Stewart \& Kamberg, 1989). The reliability of the Mobility Assessment Scale is satisfactory $(\alpha=0.92)$.

Activities of daily living. The Physical Self-Maintenance Scale (Lawton \& Brody, 1982) was used to evaluate the ability to perform activities necessary for daily life, such as toileting, feeding, dressing, grooming, ambulating, and bathing. The Physical Self-Maintenance Scale focuses on independence rather than difficulty or ability and has an internal consistency reliability of .83 (Lawton et al., 1982).

\section{Cognitive Functioning: Confusion Assessment}

Confusion Assessment is a 3-item scale and was filled out by an interviewer blind to the hypotheses, evaluating difficulty in focusing attention, disorganized or incoherent speech, and the level of consciousness.

\section{Psychological Functioning}

The following measures were used to assess patients' psychological functioning.

Geriatric Depression Scale. The Geriatric Depression Scale is a 15item scale that measures aspects of mood, such as satisfaction with life, motivation, helplessness, memory problems, and feelings of worth. This scale provides a valid, reliable, and internally consistent measure of depression in elderly patients (Brink et al., 1982; Koenig, Meador, Cohen, \& Blazer, 1988; Yesavage, Brink, Rose, \& Adey, 1983; Yesavage, Brink, Rose, \& Lum, 1983).

Will to Function. We included a 7-item scale (Hays, Sherbourne \& Mazel, 1993), evaluating aspects of the will to function, such as help seeking.

Self-Esteem Scale. The 10-item Rosenberg Self-Esteem Scale was used to measure self-esteem (Rosenberg, 1965) and is considered appropriate for elderly subjects (Crandall, 1973). This scale has high levels of reliability and validity (Crandall, 1973; Silber \& Tippett, 1965).

Three video clips were extracted from each of 57 dyadic interactions between therapists and geriatric clients by a research assistant. The 57 sessions were comprised of interactions among 11 physical therapists interacting with 44 patients (there were 57 dyads because some therapists interacted with more than 1 patient; the next section on the unit of analysis discusses this issue further). The research assistant was instructed to extract the video clips at random, with the stipulation that the camera should focus on the therapist with the patient's back toward the camera. Three 20-s clips were extracted from each videotaped interaction. One clip was taken by randomly stopping the tape within the first $10 \mathrm{~min}$ of the session, one clip was taken similarly from the middle $10 \mathrm{~min}$ of the session, and the last clip was taken from the last $10 \mathrm{~min}$ of the session. The order of the clips was randomized in a Latin square-like design. The 171 clips ( 3 clips each of 57 interactions) were recorded onto a master tape. To control for any biasing effects due to the order of presentation, we made another master tape by reversing the order of the 171 clips.

\section{Phase 2: Evaluating Nonverbal Behavior}

Participants (judges). Clips were judged by 12 undergraduate students who rated silent video clips in three ratings sessions. Judges were told that they would see short segments of physical therapy sessions and would be asked to rate therapists' nonverbal behavior on a variety of dimensions. Therapists' behavior in each clip was rated on 17 interpersonal affective dimensions on a 9-point scale, ranging from 1 (not at all) to 9 (very). The dimensions rated were selected from those used in previous research, using thin slices to examine health care interactions (Blanck, Rosenthal, Vannicelli, \& Lee, 1986; Learman, Avorn, Everitt, \& Rosenthal, 1990). Dimensions rated included how accepting, aloof, attentive, competent, concerned, confident, dominant, empathic, enthusiastic, honest, infantilizing, likable, 
nervous, optimistic, professional, supportive, and warm the therapist appeared to be. These dimensions are referred to as molar behaviors in the rest of this article. Six judges ( 3 male, 3 female) rated the original master tape, and 6 judges rated the clips in the reverse order. If requested, a clip was shown twice. Judges were not given any training and were told to rely on their intuition, as is customary in most research that uses thin-slice judgments (Ambady et al., 2000). In an effort to ensure that judges rated therapist behavior independent of the patient, the back of the patient was facing the camera in all clips so that patients' facial expressions could not influence the judges' ratings.

Coding specific nonverbal behaviors. Two undergraduates coded a number of potentially relevant nonverbal behaviors from the thin-slice clips. The frequencies of these behaviors were coded for each 20-s clip. These behaviors included the following: smiles, laughs, frowns, head nods, head shakes, shrugs, gesturing, fidgeting, pointing, leaning toward the client, and sitting versus standing. Some of these behaviors (i.e., fidgeting, pointing, and gesturing) occurred only rarely and were dropped from further analysis. The final set of variables included smiles, frowns, nods, head shakes, shrugs, forward leans, looks away, and sitting.

\section{Results and Discussion}

\section{Data Reduction: Principal-Components Analysis}

To reduce the 17 molar variables and form composite variables, we conducted a principal-components analysis. The mean of the judges' ratings for each of the 17 variables was computed for each dyad and was subjected to a principal-components analysis. The principal-components analysis yielded four interpretable components or composite variables. The composite variable "positive affect" was comprised of the average of the mean ratings of 11 variables (warm, likable, optimistic, empathic, enthusiastic, supportive, accepting, concerned, honest, attentive, and not aloof), and the composite variable "professional" was comprised of the average of the mean ratings of 4 variables (confident, competent, dominant, and professional). Two variables, "nervous" and "infantalizing," loaded onto separate composites and were therefore considered as separate variables. Intercorrelations of the variables within each new composite variable and between the new composite variables provided strong support for the four-composite solution.

\section{Reliability of Judges' Ratings}

Reliabilities for each composite variable are reported in Table 1. Effective reliabilities (Cronbach's alpha) ranged from .75 to .89 , with a mean of .84 , indicating that there was a high degree of consensus among judges. These reliabilities are displayed in the first column of Table 1 . The second column of Table 1 displays the reliability of a single judge.

Table 1

Reliabilities of Composite Variables

\begin{tabular}{lcc}
\hline \multicolumn{1}{c}{ Variable } & $R(12$ judges $)$ & $r$ \\
\hline Infantilizing-distancing & .88 & .38 \\
Nervousness & .84 & .30 \\
Positive affect & .89 & .40 \\
Professionalism & .75 & .20 \\
$\quad M$ & .84 & .32 \\
\hline
\end{tabular}

\section{Behaviors Associated With Molar Judgments}

To understand the nature of the composites, we examined the specific nonverbal behaviors that were related to each composite variable. Table 2 displays the correlations between molecular nonverbal behaviors and the molar composite variables. The judgment of infantilization was associated with a clear pattern of behaviors involving a lack of smiling $(r=-.28, p<.05)$, looking away $(r=-.33, p<.01)$, and sitting $(r=.30, p<.05)$. This suggests that judges interpreted infantilizing in the video channel to mean distancing or a lack of interest in the client. Thus, infantilization seems to be interpreted somewhat differently through the visual as compared with the vocal channel. In the visual channel, infantilization was associated with not smiling, remaining seated, and not looking at the client, behaviors which would seem to communicate a distancing message to the client, in contrast to the association of infantilization with patronizing behavior in previous research examining the vocal channel (Caporael et al., 1983; O'Connor \& Rigby, 1996). A possible line of future research is the careful delineation of the nonverbal vocal and visual correlates of infantilization. Unfortunately, because of the poor sound quality of the tapes, we were not successful in obtaining ratings of the vocal channels in the present research. For ease of interpretability, and to distinguish infantilization from its association with patronizing behavior and babytalk in the vocal channel, we shall refer to this variable as distancing in the rest of this article.

Positive affect was associated with fewer shrugs $(r=-.29, p<$ $.05)$, professionalism with fewer nods $(r=-.28, p<.05)$, and nervousness with fewer head shakes $(r=-.26, p<.05)$.

\section{Unit of Analysis}

All further analyses used the dyad as the unit of analysis rather than the therapist or the patient. Recall that although only 11 therapists participated in the study, a total of 57 dyads comprised the data set. Because the therapist-client relationship (to which certainly client characteristics may contribute) is unique to each dyad, the dyad was chosen as the unit of analysis. Although some clients interacted with multiple therapists and appeared in multiple dyads, clients' backs were to the camera in all the clips. For each of the 6 therapists who interacted with multiple patients $(M=3.5$ patient per therapist), an intraclass correlation was computed to examine the consistency of judgments of individual therapists for each of the composite variables. The low correlations suggest that there were no large therapist effects and that there was considerable variability in the behavior of each therapist across the clips in which that therapist was present differentially across clients (the average intraclass $r$ s were, $r=.17$ for positive affect, $r=.02$ for professionalism, $r=.03$ for nervousness, $r=.10$ for distancing).

In the following section, we present results examining composite variables as predictors of client physical, cognitive, and psychological outcomes. In measuring the relationship between therapists' behaviors and clients' physical and cognitive outcomes, we used a difference score as a measure of clients' improvement from admission to discharge and from admission to 3 months after discharge, and divided the change by the clients' level of functioning at admission to control for clients' functioning at admission. Because of logistical issues, we were not able to obtain 
Table 2

Physical Therapists' Molecular Nonverbal Behaviors as Predictors of Molar Variables

\begin{tabular}{lcccc}
\hline \multicolumn{1}{c}{ Behavior } & Positive affect & Professional & Nervous & Distancing \\
\hline Smile & .01 & .01 & -.01 & $-.28^{*}$ \\
Frown & -.19 & -.16 & .04 & -.09 \\
Nod & -.21 & $-.28^{*}$ & -.06 & .06 \\
Head shake & -.07 & -.14 & $-.26^{*}$ & -.14 \\
Shrug & $-.29^{*}$ & -.13 & .19 & .16 \\
Forward lean & -.03 & -.03 & .09 & .08 \\
Look at & -.04 & .10 & .12 & $-.33^{* *}$ \\
Sit & .06 & -.12 & -.18 & $.30^{*}$ \\
\hline
\end{tabular}

Note. The correlations reported are Pearson $r$ s. $n=57$.

$* p<.05$. $* * p<.01$.

measures of psychological status at admission. Thus, we report only the relationship between physical therapists' behaviors and psychological outcomes at discharge.

\section{Clients' State at Admission and Physical Therapists' Behavior}

Did physical therapists' behavior vary, depending on the physical and cognitive state of the client at admission? There were no significant relationships between physical therapists' behavior and clients' physical functioning at admission. However, therapists showed more positive affect toward clients who were more confused at admission $(r=.27, p<.05)$.

\section{Physical Therapists' Molar Behaviors as Predictors of Clients' Physical Improvement}

Recall that to control for the state of the client at admission, all the following analyses indexed improvement in the client's functioning by subtracting the clients' scores at admission from their scores at discharge or at 3 months following discharge and dividing the difference by their scores at admission. Thus, we indexed the improvement of each client relative to his or her baseline functioning at admission.

Improvement from admission to discharge. As Table 3 indicates, therapists' distancing behavior significantly predicted a decrease in clients' activities of daily living from admission to discharge $(r=-.34, p<.01)$.

Improvement from admission to 3 months following discharge. As displayed in Table 3, physical therapists' distancing behavior predicted a decrease in activities of daily living from admission to 3 months following discharge $(r=-.35, p<.05)$. In addition, therapists' professional and nervous behaviors were associated with a decrease in mobility $(r=-.51$ and $r=-.52, p<.0005$, respectively).

\section{Physical Therapists' Molar Behaviors as Predictors of Clients' Cognitive Improvement}

Improvement from admission to discharge. Correlations between physical therapists' molar behaviors and client cognitive outcomes are displayed in Table 4. Judgments of physical therapists' distancing behavior was associated with an increase in
Table 3

Change in Clients' Physical Functioning in Relation to Physical Therapists' Molar Behavior

\begin{tabular}{|c|c|c|c|c|}
\hline \multirow[b]{2}{*}{ Measure } & \multicolumn{4}{|c|}{ Molar composites } \\
\hline & Positive affect & Professional & Nervous & Distancing \\
\hline \multicolumn{5}{|c|}{ Change from admission to discharge $(n=51)$} \\
\hline Mobility & -.13 & -.09 & .09 & .02 \\
\hline $\begin{array}{l}\text { Activities of } \\
\text { daily living }\end{array}$ & -.21 & -.17 & -.09 & $-.34 * *$ \\
\hline \multicolumn{5}{|c|}{ Change from admission to 3 months from discharge $(n=43)$} \\
\hline Mobility & .22 & $-.51 * * * *$ & $-.52 * * * *$ & -.08 \\
\hline $\begin{array}{l}\text { Activities of } \\
\text { daily living }\end{array}$ & -.24 & -.16 & -.09 & $-.35^{*}$ \\
\hline
\end{tabular}

Note. The correlations reported are Pearson $r \mathrm{~s}$.

$* p<.05$. *** $p<.01$. ***** $p<.0005$.

clients' cognitive confusion $(r=.29, p<.05)$. In contrast, positive affect displayed by therapists was associated with a decrease in confusion $(r=-.27, p=.06)$.

Improvement from admission to 3 months following discharge. There were no significant correlations between judgments of physical therapists' molar behaviors and clients' cognitive differences from admission to 3 months following discharge.

\section{Physical Therapists' Molar Nonverbal Behavior as Predictors of Clients' Psychological Outcomes at Discharge}

As revealed by Table 5, therapists' distancing behavior during physical therapy sessions was negatively correlated with degree of depression $(r=-.27, p<.05)$, as was therapists' professional behavior $(r=-.35, p<.01)$. In contrast, therapists' nervousness was positively related to the will to function $(r=.29, p<.05)$.

In sum, distancing or uninvolved behavior on the part of physical therapists was associated with both short- and long-term decreases in activities of daily living and with short-term increases in confusion. Physical therapists' distancing behavior was also associated with clients' level of depression at discharge. Positive

Table 4

Change in Clients' Cognitive Functioning in Relation to Physical Therapists' Molar Behavior

\begin{tabular}{lcccc}
\hline & \multicolumn{4}{c}{ Molar composites } \\
\cline { 2 - 5 } Measure & Positive affect & Professional & Nervous & Distancing \\
\hline & Change from admission to discharge $(n=51)$ & \\
Confusion & -.27 & -.02 & .06 & $.29 *$ \\
\hline
\end{tabular}

Change from admission to 3 months from discharge $(n=43)$

$\begin{array}{lllll}\text { Confusion } & -.01 & -.20 & .25 & .10\end{array}$

Note. The correlations reported are Pearson $r \mathrm{~s}$.

$* p<.05$. 
Table 5

Clients' Psychological Functioning at Discharge in Relation to Physical Therapists' Molar Behavior

\begin{tabular}{lccc}
\hline \multicolumn{1}{c}{ Variable } & Depression & $\begin{array}{c}\text { Will to } \\
\text { function }\end{array}$ & Self-esteem \\
\hline Positive affect & -.06 & -.17 & .02 \\
Professional & $-.35^{* *}$ & -.02 & -.25 \\
Nervous & -.21 & $.29^{*}$ & -.19 \\
Distancing & $-.27^{*}$ & .01 & -.16 \\
\hline
\end{tabular}

Note. The correlations reported are Pearson $r$ s. $n=48$.

$* p<.05 . \quad * * p<.01$.

affect displays by physical therapists predicted short-term decreases in confusion, and therapists' professionalism and nervousness predicted long-term decreases in mobility.

\section{Physical Therapists' Molecular Nonverbal Behavior as Predictors of Clients' Improvement}

Finally, we examined the relationship between physical therapists' specific behaviors and outcome variables for the elderly clients, reflected in improvement from the time of admission to the time of discharge and from the time of admissions to 3 months following discharge. Table 6 displays these findings. One clear finding in this area is the positive effect of frowning $(r=.59, p<$ $.0001)$ and nodding $(r=.36, p<.01)$ on activities of daily living from admission to discharge. This effect held true for the longterm period (admission to 3 months after discharge) for both frowning $(r=.60 . p<.0001)$ and for nodding $(r=.33, p<.05)$.

Other positive effects of frowning and nodding were illustrated by the decrease in confusion between admission and discharge ( $r=-.35, p<.01$, for nods; $r=-.26, p<.08$, for frowns). Smiling predicted an improvement in mobility from admission to 3 months after discharge $(r=.26, p<.05)$. Finally, shrugging was associated with a decrease in mobility from admission to discharge $(r=-.44, p<.0001)$, and head shaking was associated with a decrease in confusion from admission to 3 months after discharge $(r=-.31, p<.05)$. No molecular behaviors were associated with clients' psychological functioning at discharge.

On the basis of these findings, the three molecular behaviors associated with positive client outcome (frowning, nodding, and smiling) were $Z$ scored and combined to form a composite nonverbal behavior, "facial expressiveness." Further analyses revealed that facial expressiveness was associated with a substantial improvement in activities of daily living from admission to discharge $(r=.60)$ and with a decrease in confusion from admission to discharge $(r=-.41)$.

Thus, the findings in regard to therapists' distancing behavior were quite striking. The clients of physical therapists who were judged by naive raters to display a high degree of distancing behavior showed decreases in both physical and cognitive functioning from admission to discharge, and the decrease in physical functioning held stable for the 3 months following discharge. Note that distancing was the only variable associated with both shortand long-term health outcomes.

The findings in regard to facial expressiveness molecular composite are also noteworthy. Physical therapists' facial expressiveness—-smiling, nodding, and frowning-was associated with short- and long-term improvements in physical and cognitive functioning of the clients', after controlling for the physical and cognitive state of the client at admissions. One possible explanation for these findings is that facial expressiveness communicates empathy and concern for the client thus promoting patient satisfaction and health improvements. This speculation falls in line with previous research indicating that combination of caring and concern results in the highest levels of patient satisfaction (Hall et al., 1981). The results of this study suggest that such behaviors may also be related to improvements in clients' physical and cognitive functioning. This also falls in line with Carl Rogers's (1975) contention that empathy is a powerful therapeutic intervention. Empathy, however, is a vague concept and is difficult to teach. This study suggests that certain specific behaviors of providers are associated with the communication of empathy. Another possibility is that providers were able to assess the prognosis of their clients and communicated these expectations through their nonverbal behaviors. Thus, providers might have behaved more

Table 6

Physical Therapists' Nonverbal Behaviors as Predictors of Clients' Outcomes

\begin{tabular}{|c|c|c|c|c|c|c|c|c|c|}
\hline \multirow[b]{2}{*}{ Behavior } & \multicolumn{3}{|c|}{ Admission to discharge } & \multicolumn{3}{|c|}{$\begin{array}{c}\text { Admission to } 3 \text { months } \\
\text { after discharge }\end{array}$} & \multicolumn{3}{|c|}{ At discharge } \\
\hline & Mobility & ADL & Confusion & Mobility & ADL & Confusion & Depression & WTF & Self-esteem \\
\hline$n$ & 51 & 51 & 50 & 43 & 43 & 41 & 48 & 48 & 48 \\
\hline Smile & .14 & .24 & -.19 & $.26^{*}$ & $.26^{*}$ & .04 & .08 & .02 & .03 \\
\hline Frown & .09 & $.59 * * *$ & $-.35 * *$ & .07 & $.60 * * *$ & .02 & .03 & -.20 & -.05 \\
\hline Nod & -.03 & $.36^{* *}$ & -.26 & .04 & $.33^{* *}$ & .17 & .18 & .07 & .14 \\
\hline Head shake & -.09 & -.08 & .06 & .09 & -.08 & $-.31^{*}$ & .03 & -.13 & -.01 \\
\hline Shrug & $-.44 * * *$ & .02 & .00 & -.15 & -.06 & -.09 & .16 & .24 & .17 \\
\hline Forward lean & .14 & -.17 & .00 & .02 & -.20 & .15 & .26 & .10 & .14 \\
\hline Look at & .13 & -.04 & -.18 & -.13 & -.05 & .23 & -.08 & -.02 & -.16 \\
\hline Sit & -.04 & -.21 & .10 & .05 & -.23 & -.07 & -.06 & -.09 & -.02 \\
\hline Facial affect composite & .08 & $.60 * * *$ & $-.41 * *$ & .18 & $.58 * * *$ & .14 & .17 & -.02 & .16 \\
\hline
\end{tabular}

Note. The correlations reported are Pearson $r \mathrm{~s}$. ADL $=$ Activities of Daily Living Scale; WTF $=$ Will to Function Scale.

$* p<.05$. ** $p<.01$. *** $p<.001$. 
expressively toward clients for whom they had more positive expectations. Interpersonal expectations are often subtly and nonconsciously communicated through nonverbal behavior (Rosenthal, 1987; Rosenthal \& Rubin, 1978).

Given these results regarding the relationship between physical therapists' behavior, especially distancing behavior, and elderly clients' health outcome, we became interested in further examining one potential mechanism underlying the relationship between therapist behaviors and client health outcome: client perception. Do clients perceive the distancing molecular nonverbal behaviors associated with distancing as indifference to their well-being? Such perceptions might result in poor health outcomes. For example, if distancing behavior is perceived negatively, then elderly client recipients of such behavior might be prone to withdraw from the relationship, and such a withdrawal could certainly cause future health problems due to the client's reluctance to broach health concerns or even to keep medical appointments. Thus, in Study 2, we explored elderly participants' perceptions of different provider behaviors.

\section{Study 2: Perceptions of Physical Therapists' Behaviors}

This study examined elderly participants' perceptions of physical therapists' communicative behavior patterns. The goal was to investigate how elderly adults perceived the interpersonal characteristics of providers displaying the nonverbal behavior patterns associated in Study 1 with clients' health care outcomes. Elderly participants' reactions to three specific behavioral patterns were of interest. One nonverbal behavior pattern of interest was facial expressiveness, the composite of smiling, nodding, and frowning. Recall that this pattern was associated with client improvements in Study 1. In addition, we were interested in the composite of looking away from the patient and not smiling, linked to perceptions of distancing and poor patient outcomes in the previous study.

Adults over the age of 60 viewed examples of these three behavioral patterns spontaneously produced by the physical therapists in Study 1 and rated the physical therapists on several dimensions.

\section{Method}

\section{Phase 1: Creating Stimulus Tapes}

Of the 171 clips created for Study 1, 24 were extracted to be viewed by older adult participants in Study 2. Eight clips deemed most representative of each of the three behavior patterns, based on the ratings obtained in Study 1, were used. These categories were facial expressiveness (the combination of smiling, frowning and nodding), positive affect (the combination of smiling and nodding), and withdrawal (the combination of not smiling and looking away). Clips that had the highest mean ratings in each of the three categories and that did not overlap with other categories were selected for this study.

\section{Phase 2: Evaluating Nonverbal Behavior}

Participants (judges). Clips were judged by 14 participants, ranging in age from 63 to 81 years. Judges included 12 women and 2 men. Judges were recruited from the Boston area by using a database of elderly participants made available by researchers from a nearby laboratory. Judges were paid $\$ 20$ plus the cost of transportation for their participation.
Procedure. Judges were run individually by a research assistant. On arrival to the laboratory, they were escorted to a small room and were given instructions on rating the video clips. Judges were told that they would see short silent video segments of physical therapy sessions and would be asked to rate physical therapists on a variety of dimensions. Judges were instructed to rate each physical therapist immediately after viewing each video clip, and they were directed to push the stop button on the VCR to give themselves plenty of time to make their ratings. In an effort to ensure that participants understood the directions and were comfortable with the procedures, all participants completed $2-4$ practice sessions in which they viewed 10-s silent video clips used in an unrelated study and used the rating scales designed for the present study.

Coding molar variables. Therapists' behavior in each clip was rated on six interpersonal affective dimensions on a 7-point scale, ranging from 1 (not at all) to 7 (very). The molar variables rated included the following: warm, caring, concerned, empathic, indifferent, and distancing/ infantilizing.

\section{Results and Discussion}

\section{Data Reduction}

To reduce the data and increase the stability of the interpersonal affective dimensions, we conducted principal-components analyses. First, the mean of the judges' ratings of each of the 6 dimensions was computed across the 24 clips. These means were subjected to principal-components analysis with varimax rotation. The two-factor solution with varimax rotation provided the clearest solution, indicating the presence of two composites. On the basis of these results, 4 variables (warm, concerned, caring, and empathic) were summed to create the composite variable "positivity" and 2 variables (indifferent, distancing) were summed to create the composite variable "negativity." The standard deviations of the variables were similar enough so that transformations into standard scores were not needed before combining the variables. Correlational analyses revealed that the variables within each composite correlated much more highly with each other than they did with the variables comprising the other composites. Thus, the average intercorrelation among the variables comprising the composite "positivity" was $r=.96$. The average intercorrelation among the variables comprising the "negativity" composite was also high $(r=.45)$.

\section{Positivity}

A one-way analysis of variance (ANOVA) revealed a significant main effect for molecular behavior pattern on mean positivity ratings, $F(2,21)=15.20, p<.00001$. Two patterns of molecular behavior, facial expressiveness and positive affect, were rated more positively ( $M=5.45$ and 5.74 , respectively) than the "withdrawn" pattern $(M=4.10)$.

\section{Negativity}

For negativity ratings, a one-way ANOVA revealed a significant main effect for molecular behaviors, $F(2,21)=20.28, p<$ .00001 . The withdrawn pattern was rated more negatively $(M=3.40)$ than both the facially expressive pattern $(M=2.33)$ and the positive-affect pattern $(M=2.26)$.

These findings support those of the previous study by demonstrating that naive older adult participants responded differently to 
specific combinations of nonverbal behaviors of health care providers. Older participants' ratings of physical therapists along several interpersonal, affective dimensions differed as a function of the nonverbal behavior patterns of therapists. Specifically, the composite behavioral patterns of smiling, nodding, and frowning, and smiling and nodding were rated most positively (as defined the variables warmth, caring, concerned, and empathic) and least negatively (as defined by the variables indifferent and distancing). It is interesting to note that the combination of not smiling and looking away was associated with the perception of both indifference and distancing/infantilization. In general, these results suggest that clients' perceptions of these nonverbal behaviors might be related to their improvement and outcomes.

\section{General Discussion}

These studies reveal that the nonverbal behavior of health care providers is associated with both the perceptions and therapeutic outcomes of their clients. Although Study 1 suggested the potential beneficial effects of facial expressiveness (as revealed by the combination smiling, nodding, and frowning) and the negative consequences of distancing and indifference (as revealed by not smiling and looking away), Study 2 indicated that these behaviors are differentially perceived by the elderly as positive or negative.

The facial expressiveness (i.e., smiling, nodding, furrowed brows) of physical therapists was associated with an improvement in elderly clients' activities of daily living from admission to discharge and with a decrease in confusion from admission to discharge. It was speculated following Study 1 that facial expressiveness communicates engagement and concern for the client, thereby promoting patient satisfaction and health improvements. Results of Study 2 confirmed this prediction: Here, therapists who exhibited facial expressiveness and positive affect were perceived as more warm, caring, concerned, and empathic. At the same time, they were perceived as less indifferent and distancing.

These results highlight the importance of health care providers' nonverbal behavior in the therapeutic exchange in a dyad. This is especially true in regard to distancing behavior by the physical therapists that was associated with a paradoxical outcome in the clients. Recall that distancing was associated with long-term negative consequences for cognitive and physical functioning. The results of Study 2, which used relatively independent elderly individuals as participants, suggest that distancing is perceived negatively by this population.

One plausible explanation for the results showing that physical therapists' behaviors was linked to clients' outcomes might be that the physical therapists' behavior revealed their expectations for client's outcomes. ${ }^{1}$ Perhaps providers are able to gauge the potential improvement of patients, and their behavior reflects and communicates these expectations. A great deal of research has shown that interpersonal expectations are often communicated quite subtly through nonverbal behavior (Ambady et al., 2000). It is conceivable that clients sensed these expectations and confirmed them (Rosenthal \& Rubin, 1978). Further work is needed to examine this possibility.

It is not surprising that these studies support the idea that patient perceptions might moderate the effects of providers' nonverbal behavior patterns on therapeutic outcome. Previous work on elderspeak (Caporael, Lukaszewski, \& Culbertson, 1983; O’Connor
\& Rigby, 1996) has found that secondary baby talk is perceived differentially as a function of patient characteristics. These studies have found that patient functioning prior to treatment plays an important role in the perception of secondary baby talk as warm and nurturing or demeaning and disrespectful. For example, in the study by Caporael et al. (1983), lower functioning residents of a nursing home tended to prefer baby talk, perhaps because they desired more nurturance. In contrast, the negative perceptions of distancing behavior in the present study may have been driven by the relative independence of the elderly participants. Thus, it seems that as dependence on caregivers increases, so does the preference for a pattern of nonverbal behavior that signals a lack of respect and patronization.

A few important limitations of this work should be kept in mind. The major limitation of the first study is that it was correlational. We focused on the nonverbal behavior patterns of only one half of the patient-therapist interaction: the therapist, but the unit of the analysis was the dyad. The angle of the camera prevented us from being able to examine the clients' behavior. But the patienttherapist interaction is a dynamic one in which the thoughts and behavior of one interactant are constantly responding to and influencing those of the other interactant. Additional studies separately examining therapist behavior, client behavior, as well as the interaction, would further our understanding of the dynamics of patient-physician communication. We hope that in the future, randomized experimental studies with physicians and elderly patients will examine these phenomena more systematically. Moreover, this study examined reactions and perceptions to nonverbal behavior as displayed mostly through facial expression and gestures. Additional channels, such as speech and vocal tone, should be examined to expand on the present findings. These channels may provide particular insights as to evaluative perceptions of distancing and anxious caregiver behavior. For instance, anxiety as judged from the vocal channel may communicate concern in a manner similar to the facial expressiveness composite examined in this article (Milmoe et al., 1967).

In sum, these studies suggest that providers' nonverbal communication, particularly facial cues and gestures, are associated with elderly clients' improvement as well as elderly clients' perceptions of caregivers in medical interactions. They, thus, add to the burgeoning evidence linking physician-patient communication to important outcomes, such as patient dissatisfaction and poor health outcomes (Bensing, 1991; Ben-Sira, 1980; DiMatteo, Prince, \& Hays, 1980; Hall et. al., 1981; Lepper et al., 1995; White et al., 1994; Woolley et al., 1978). These studies also suggest that the physician communicates a wealth of information by means of minimal cues that can have important consequences. They indicate that in the complex interaction between health care providers and their elderly clients, how a message is conveyed might be as important as what a message conveys.

\footnotetext{
${ }^{1}$ We thank an anonymous reviewer for this suggestion.
}

\section{References}

Adelman, R. D., Greene, M. G., Charon, R., \& Friedmann, E. (1992). The content of physician and elderly patient interaction in the medical primary care encounter. Communication Research, 19, 370-380. 
Ambady, N., Bernieri, F., \& Richeson, J. (2000). Towards a histology of social behavior: Judgmental accuracy from thin slices of behavior. In M. P. Zanna (Ed.), Advances in experimental social psychology, 32, 201-272.

Ambady, N., \& Rosenthal, R. (1992). Thin slices of behavior as predictors of interpersonal consequences: A meta-analysis. Psychological Bulletin, 2, 256-274.

Beisecker, A. E., \& Beisecker, T. D. (1990). Patient information seeking behaviors when communicating with doctors. Medical Care, 28, 19-28.

Bensing, J. (1991). Doctor-patient communication and the quality of care. Social Science and Medicine, 32, 1301-1310.

Ben-Sira, Z. (1980). Affective and instrumental components in the physician-patient relationship: An additional dimension of interaction theory. Journal of Health and Social Behavior, 21, 170-180.

Blanck, P. D., Rosenthal, R., \& Vannicelli, M. (1986). Talking to and about patients: The therapist's tone of voice. In P. D. Blanck, R. Buck, \& R. Rosenthal (Eds.), Nonverbal communication in the clinical context. University Park, PA: Penn State University Press.

Blanck, P. D., Rosenthal, R., Vannicelli, M., \& Lee, T. D. (1986). Therapist's tone of voice: Descriptive, psychometric, interactional, and competence analyses. Journal of Social and Clinical Psychology, 4, 154178 .

Brink, T. L., Yesavage, J., Lum, O., Heersema, Adey, M., \& Rose, T. L. (1982). Screening tests for geriatric depression. Clinical Gerontologist, 1, 37-44.

Caporael, L. R. (1981). The paralanguage of caregiving: Baby talk to the institutionalized aged. Journal of Personality and Social Psychology, 40, 876-884.

Caporael, L. R., \& Culbertson, G. H. (1986). Verbal response modes of baby talk and other speech at institutions for the aged. Language and Communication, 6, 99-112.

Caporael, L. R., Lukaszewski, M. P., \& Culbertson, G. H. (1983). Secondary baby talk: Judgments by institutionalized elderly and their therapists. Journal of Personality and Social Psychology, 44, 746-754.

Coupland, N., Coupland, J., \& Giles, H. (1991). Language, society and the elderly: Discourse, identity, and ageing. Oxford, England: Basil Blackwell.

Crandall, R. (1973). The measurement of self-esteem and related constructs. In J. R. Robinson \& P. R. Shaver (Eds.), Measures of social psychological attitudes (pp. 45-167). Ann Arbor, MI: Institute for Social Research.

D'Augelli, A. R. (1974). Nonverbal behavior of helpers in initial helping interactions. Journal of Counseling Psychology, 21, 360-363.

DePaulo, B. M. (1992). Nonverbal behavior and self-presentation. Psychological Bulletin, 11, 203-243.

Devine, E. C., \& Cook, T. D. (1985). A meta-analytic analysis of the effects of psychoeducational interventions on length of post-surgical hospital stay. Nursing Research, 32, 267-274.

DiMatteo, M. R., \& Friedman, H. S. (1982). Social psychology and medicine. Cambridge, MA: Oelgeschlager, Gunn, \& Hain.

DiMatteo, M. R., Prince, L. M., \& Hays, R. (1980). Nonverbal communication in the medical context: The physician-patient relationship. In P. D. Blanck, R. Buck, \& R. Rosenthal (Eds.), Nonverbal communication in the clinical context (pp. 74-98). University Park, PA: Penn State University Press.

Ekman, P., \& Friesen, W. V. (1969). Nonverbal leakage and clues to deception. Psychiatry, 32, 88-105.

Ekman, P., \& Friesen, W. V. (1974). Nonverbal behavior and psychopathology. In R. J. Friedman \& M. M. Katz (Eds.), The psychology of depression: Contemporary theory and research. Washington, DC: Winston and Sons.

Fretz, B. R., Corn, R., Tuemmler, J. M., \& Bellet, W. (1979). Counselor nonverbal behaviors and client evaluations. Journal of Counseling Psychology, 26, 304-311.
Friedman, H. S., \& DiMatteo, M. R. (Eds.). (1982). Interpersonal issues in health care. New York: Academic Press.

German, P. S., Shapiro, S., Skinner, E. A., Von Korff, M., Klein, L. E., Turner, R. W., et al. (1987). Detection and management of mental health problems of older patients by primary care providers. Journal of the American Medical Association, 257, 489-493.

Greene, M. G., Adelman, R., Charon, R., \& Hoffman, S. (1986). Ageism in the medical encounter: An exploratory study of the doctor-elderly patient relationship. Language \& Communication, 6, 113-124.

Greenfield, S., Kaplan, S. H., \& Ware, J. E., Jr. (1985). Expanding patient involvement in care: Effects on patient outcomes. Annals of Internal Medicine, 102, 520-528.

Greenfield, S., Kalpan, S. H., Ware, J. E., Jr., Yano, E. M., \& Frank, J. H. (1988). Patients' participation in medical care: Effects on blood sugar control and quality of life in diabetes. Journal of General Internal Medicine, 3, 448-457.

Hall, J. A., \& Dornan, M. C. (1988). What patients like about their medical care and how often they are asked: A meta-analysis of the satisfaction literature. Social Science and Medicine, 27, 935-939.

Hall, J. A., Harrigan, J. A., \& Rosenthal, F. (1995). Nonverbal behavior in clinician-patient interaction. Applied and Preventive Psychology, 4, 21-37.

Hall, J. A., Roter, D. L., \& Rand, C. S. (1981). Communication of affect between patient and physician. Journal of Health and Social Behavior, 22, 18-30.

Harrigan, J. A., Oxman, T. E., \& Rosenthal, R. (1985). Rapport expressed through nonverbal behavior. Journal of Nonverbal Behavior, 9, 95-110.

Harrigan, J. A., \& Rosenthal, R. (1983). Physicians' head and body positions as determinants of perceived rapport. Journal of Applied Social Psychology, 13, 469-509.

Hasse, R. F., \& Tepper, D. T. (1972). Nonverbal components of empathic communication. Journal of Counseling Psychology, 19, 417-424.

Hays, R. D., Sherbourne, C. D., \& Mazel, R. E. (1993). The RAND 36-item health survey 1.0. Health Economics, 2, 217-227.

Hermansson, G. L., Webster, A. C., \& McFarland, K. (1988). Counselor deliberate postural lean and communication of facilitative conditions. Journal of Counseling Psychology, 35, 149-153.

Hill, C. E., \& Stephany, A. (1990). Relation of nonverbal behavior to client reactions. Journal of Counseling Psychology, 37, 22-26.

Hummert, M. L., \& Mazloff, D. (1993). Elderly adults' views of patronizing speech: A focus group study. Unpublished manuscript.

Kaplan, S. H., Greenfield, S., \& Ware, J. E. (1989). Assessing the effects of physician-patient interactions on the outcomes of chronic disease. Medical Care, 27, 110-127.

Kelly, E. W., Jr., \& True, J. H. (1980). Eye contact and communication of facilitative conditions. Perceptual and Motor Skills, 51, 815-820.

Kite, M. E., \& Johnson, B. T. (1988). Attitudes toward older and younger adults: A meta-analysis. Psychology and Aging, 3, 233-244.

Koenig, H. G., Meador, K. G., Cohen, H. J., \& Blazer, D. G. (1988). Depression in elderly hospitalized patients with medical illness. Archives of Internal Medicine, 148, 1929-1936.

Kogan, N. (1979). Beliefs, attitudes, and stereotypes about old people. Research on Aging, 1, 11-36.

LaCrosse, M. B. (1975). Nonverbal behavior and perceived counselor attractiveness and persuasiveness. Journal of Counseling Psychology, 22, 563-566.

Larsen, K. M., \& Smith, C. K. (1981). Assessment of nonverbal communication in the patient-physician interview. Journal of Family Practice, 12, 481-488.

Lawton, M. P., \& Brody, E. M. (1982). Assessment of older people: Self-maintaining and instrumental activities of daily living. Gerontologist, 9, 179-186.

Lawton, M. P., Moss, M., Fulcomer, M., \& Kleban, M. H. (1982). A 
research and service oriented multilevel assessment instrument. Journal of Gerontology, 37, 91-99.

Learman, L. A., Avorn, J., Everitt, D. E., \& Rosenthal, R. (1990). Pygmalion in the nursing home: The effects of caregiver expectations on patient outcome. Journal of the American Geriatric Society, 38, 797803

Lepper, H. S., Martin, L. R., \& DiMatteo, M. R. (1995). A model of nonverbal exchange in physician-patient expectations for patient involvement. Journal of Nonverbal Behavior, 19, 207-222.

Levin, J., \& Levin, W. C. (1980). Ageism: Prejudice and discrimination against the elderly. Belmont, CA: Wadsworth.

Levinson, W. (1994). Physician-patient communication: A key to malpractice prevention. Journal of the American Medical Association, 273, 1619-1620

Maguire, P., Fairburn, S., \& Fletcher, C. (1986). Consultation skills of young doctors: Benefits of feedback training in interviewing as students persist. British Medical Journal, 2992, 1573-1576.

Milmoe, S., Rosenthal, R., Blane, H. T., Chafetz, M. E., \& Wolf, I. (1967). The doctor's voice: Postdictor of successful referral of alcoholic patients. Journal of Abnormal Psychology, 72, 78-84.

Mumford, E., Schlesinger, H., \& Glass, G. (1982). The effects of psychological intervention on recovery from surgery and heart attacks: An analysis of the literature. American Journal of Public Health, 72, 141151.

O’Connor, B. P., \& Rigby, H. (1996). Perceptions of babytalk, frequency of receiving babytalk, and self-esteem among community and nursing home residents. Psychology and Aging, 11, 147-154.

Rime, B., \& Schiaratura, L. (1991). Gestures and speech. In R. S. Feldman \& B. Rime (Eds.), Fundamentals of nonverbal behavior. New York: Cambridge University Press.

Robbins, L. S., \& Woolf, F. M. (1989). The effect of training on medical students' response to geriatric patient concerns: Results of a linguistic analysis. Gerontologist, 29, 341-344.

Rogers, C. R. (1975). The necessary and sufficient conditions of therapeutic personality change. Journal of Consulting Psychology, 21, 995-1103.

Rosenberg, M. (1965). Society and the adolescent self-image. Princeton, NJ: Princeton University Press.

Rosenblum, N. D., Wetzel, M., Platt, O., Daniels, S., Crawford, J., \& Rosenthal, R. (1994). Predicting medical student success in a clinical clerkship by rating students' nonverbal behavior. Archives of Pediatric Adolescent Medicine, 148, 213-219.

Rosenthal, R. (1987). Pygmalion effects: Existence, magnitude, and social importance. Educational Researcher, 16, 37-41.

Rosenthal, R., \& Rubin, D. B. (1978). Interpersonal expectancy effects: The first 345 studies. Behavioral and Brain Sciences, 3, 377-415.

Roter, D. L., Hall, J. A., \& Katz, N. R. (1987). Relation between physicians' behavior and analogue patients' satisfaction, recall, and impressions. Medical Care, 25, 437-451.

Rubin, K. H., \& Brown, I. D. R. (1975). A life-span look at person perception and its relationship to communicative interaction. Journal of Gerontology, 30, 461-468.

Seay, T. A., \& Altekruse, M. K. (1979). Verbal and nonverbal behavior in judgments of facilitative conditions. Journal of Counseling Psychology, 26, 108-119.

Silber, E., \& Tippett, J. S. (1965). Self-esteem: Clinical assessment and measurement validation. Psychological Reports, 16, 1017-1071.

Smith-Hanen, S. S. (1977). Effects of nonverbal behaviors on judged levels of counselor warmth and empathy. Journal of Counseling Psychology, 24, 87-91.

Stewart, A. L., \& Kamberg, C. (1989). Physical functioning. In A. L. Stewart \& J. E. Ware (Eds.), Measuring functional status and wellbeing: The medical outcomes study approach (pp. 86-101). Durham, NC: Duke University Press.

Tepper, D. T., \& Hasse, R. F. (1978). Verbal and nonverbal communication of facilitative conditions. Journal of Counseling Psychology, 25, 35-44.

Tickle-Degnen, L. (1998). Working well with others: The prediction of students' clinical performance. American Journal of Occupational Therapy, 52, 133-142.

Tickle-Degnen, L., \& Puccinelli, N. M. (1999). The nonverbal expression of negative emotions: Peer and supervisor responses to occupational therapy students' emotional attributes. Occupational Therapy Journal of Research, 19, 1-22.

Timpton, R. M., \& Rymer, R. A. (1978). A laboratory study of the effects of varying levels of counselor eye contact on client-focused and problem-focused counseling styles. Journal of Counseling Psychology, 25, 200-204.

Weinberger, M., Greene, J. Y., \& Mamlin, J. J. (1981). The impact of clinical encounter events on patient and physician satisfaction. Social Science in Medicine, 15, 239-244.

White, J., Levinson, W., \& Roter, D. (1994). "Oh, by the way ... "The closing moments of the medical visit. Journal of General Internal Medicine, 9, 24-28.

Woolley, F. R., Kane, R. L., Hughes, C. C., \& Wright, D. D. (1978). The effects of doctor patient communication on satisfaction and outcome of care. Social Science and Medicine, 12, 123-128.

Yesavage, J., Brink, T. L., Rose, T. L., \& Adey, M. (1983). The geriatric depression rating scale: Comparison with other self-report and psychiatric rating scales. In T. Crock, S. Ferris, \& R. Bartus (Eds.), Assessment in geriatric psychopharmacology (pp. 153-163). New Canaan, CT: Mark Powley Associates.

Yesavage, J., Brink, T. L., Rose, T. L., \& Lum, O. (1983). Development and validation of a Geriatric Depression Screening Scale: A preliminary report. Journal of Psychiatric Research, 17, 37-49.

Received August 16, 2000 Revision received December 10, 2001 Accepted January 9, 2002 